\begin{tabular}{|c|c|c|}
\hline Beitr. Ent. & Keltern & ISSN 0005-805X \\
\hline $\mathbf{5 8}(2008) 1$ & S. $97-105$ & 15.07 .2008 \\
\hline
\end{tabular}

\title{
Juxtocellar Structures in Euglossine Bees: A New Character for Corbiculate Studies
}

\section{(Hymenoptera: Apidae)}

With 12 figures

Ismael A. Hinojosa-Díaz and Michael S. Engel

\section{Summary}

A new morphological structure is described and figured for orchid bees (Apinae: Euglossini). These minute features are located posterolateral to the ocelli and are termed "juxtocellar structures". The diversity of their form across Euglossini is described. Homologous structures were found in some related lineages of apid bees (e.g., Anthophorini, Centridini, Eucerini) while in others the structures were absent (e.g., Xylocopinae, Nomadinae). Most notably juxtocellar structures are apomorphically lost in all other corbiculate apine tribes (i.e., Bombini, Meliponini, Apini, Electrobombini, Electrapini, and Melikertini), a pattern which is in accordance with current phylogenetic hypotheses for the clade.

\section{Resumen}

Se describe e ilustra una estructura morfológica nueva para abejas de las orquídeas (Apidae: Euglossini). Estas diminutas estructuras, aquí nombradas "estructuras yuxtaocelares", se ubican posterolateralmente a los ocelos. Se describe la diversidad de su forma dentro de Euglossini. Estructuras homólogas fueron encontradas en algunos linajes relacionados de abejas de la familia Apidae (Anthophorini, Centridini, Eucerini), mientras que en otros las estructuras estuvieron ausentes (Xylocopinae, Nomadinae). De manera relevante las estucturas yuxtaocelares se hallan apomórficamente ausentes en todas las otras tribus de abejas con corbícula (Bombini, Meliponini, Apini, Electrobombini, Electrapini y Melikertini), lo cual concuerda con hipótesis filogenéticas actuales para este grupo.

\section{Zusammenfassung}

Es wird eine neuartige morphologische Struktur bei Prachtbienen (Apinae: Euglossini) dargestellt. Diese findet sich posterolateral der Ocelli und wird als "Juxtocellarstruktur" bezeichnet. Sie wird in ihrer Ausprägung bei den Euglossinen beschrieben. Homologe Strukturen wurden bei verschiedenen verwandten Gruppen von Apidae gefunden, z. B. bei Anthophorini, Centridini und Eucerini, während sie bei anderen fehlen, z. B. bei Xylocopinae und Nomadinae. Bemerkenswerterweise sind Juxtocellarstrukturen verlorengegangen als Apomorphie bei allen anderen korbikulaten Triben der Apidae (darunter die Bombini, Meliponini, Apini, Electrobombini, Electrapini und Melikertini), ein Merkmalsmuster, das mit den aktuellen phylogenetischen Hypothesen dieser Gruppe übereinstimmt.

\section{Keywords}

Apoidea, Anthophila, comparative morphology, Euceriti, Apiti, phylogeny. 


\section{Introduction}

The bee tribe Euglossini has captured the attention of entomologists for their astonishing external morphology (particularly their distinctive metallic integumental coloration and peculiar anatomical modifications), their particular biological association with Orchidaceae (hence their name "orchid bees"), and their phylogenetic position among other corbiculate apine bees. Aside from their remarkable biology and their eye-catching coloration, these bees have numerous interesting morphological features that have been extensively employed in their taxonomy, especially the length of the labiomaxillary complex and the secondary sexual characters of males. More recently, however, studies have rightly begun to venture away from such traditional characters and to explore often ignored or under-utilized character systems in order to provide a modern comprehensive picture of euglossine diversity and evolution (e.g., male terminalic structures: Hinojosa-DíAz \& Engel, 2007; Hinojosa-Díaz, in prep.). This brief contribution provides an account of one such novel character system and discusses some of its potential implications for the orchid bees and their relatives.

As part of a morphological phylogenetic study of the genus Euglossa (Hinojosa-Díaz, in prep.) it was noticed that peculiar juxtocellar structures occurred across the group.

Species of Euglossa reviewed included representatives of all subgenera and species groups as recognized by Cockerell (1917), Moure (1967, 1989), and Dressler (1978, 1982a, 1982b, 1982c). Euglossines of all other genera were similarly studied as well as other corbiculates (extant and extinct) and Apinae, particularly the tribes Centridini, Anthophorini, and Eucerini. Herein we provide a brief overview of these structures in order to draw them to the attention of melittologists and to highlight the apparent phylogenetic utility of these features.

\section{Material and Methods}

Scanning electron microscope images were produced for selected specimens as shown in the next section. Specimens were dissected, mounted on microscopy stubs, coated in gold, and examined using a Zeiss LEO-1550 Field Emission Scanning Electron Microscope. In order to reveal some internal integumental connection with the juxtocellar structures the head of one specimen of Euglossa (Glossura) imperialis CocKerell was treated in a highly-concentrated solution of KOH for enough time as to reveal the internal sclerotic structures of the head.

\section{Juxtocellar Structures}

The juxtocellar structures as defined here correspond to minute, external cuticular modifications located on the vertex, posterolateral to both lateral ocelli, hence the name "juxtocellar" (L. juxta = "near" and ocellus = "little eye") (Fig. 1). The morphological variation of these structures is discussed in this section for each taxon reviewed, taking as a base the characterization of them as observed in Euglossa.

\section{Euglossini:}

In both sexes of all species of Euglossa the juxtocellar structures are minute tubercles located posterolaterally to the lateral ocelli, from which they are separated by about 0.3-0.5 ocellar diameters. These sometimes faint, domelike tubercles are generally oval in shape as seen from 
above, with their longitudinal axes running slightly oblique such that the anterior extreme is closer to the ocellus than the posterior one. The juxtocellar tubercles in Euglossa are dark brown, matte, contrasting with the metallic iridescence of the surrounding integument; this makes them noticeable if seen with enough magnification. There are no setae arising from them and the upraised integument that comprises them is minutely concentric-rugulose. No pores or any kind of cuticular opening is present in the juxtocellar tubercles. In all Euglossa species the tubercles are aligned with the posterior extreme of the lateral ocelli, occupying an inner-median position with respect to the longitudinal axis of the body and in the shallow concavity formed between the compound eye, the lateral ocellus, and the posterior section of the vertex. A connection between the juxtocellar tubercle and the lateral ocellus is noticeable as the bulging integument surrounding the ocellus is interrupted in a narrow area aligned with the anterior extreme of the tubercle (Figs 2-4). There is no connection of the juxtocellar tubercles with any sclerotic structure inside the head capsule of Euglossa as revealed in cleared material.

Variation of these structures in Euglossa involves the orientation, size, and shape. Although in most species the tubercles are slightly oblique, as described above, in E. (Dasystilbe) villosa Moure they are longitudinally aligned with the longitudinal axis of the body, while in some species of the subgenera Glossura and Glossuropoda the oblique angle formed with the longitudinal axis of the body is of about $45^{\circ}$. Size and shape are features seemingly correlated as in those species in which the tubercles are proportionally larger (around 0.3 ocellar diameter), they also appear as enlarged ovals, while in those species in which the tubercles are proportionally smaller $(0.2$ ocellar diameter), the shape is almost circular. Examples of the first condition occur in Glossura and Glossuropoda, the second being found in some species of Glossurella.

In the other euglossine genera (Eufriesea, Eulaema, Exaerete, and Aglae) the juxtocellar tubercles show the same general structure as described for Euglossa, with the following remarks. The projecting tubercles in the four genera are circular at their bases, while in most Euglossa they are oval as described above. The apex of the tubercle is directed laterally in all these genera except Aglae (vide infra), while in Euglossa the projections are mostly directed upwards and outwards. The location of these structures is also posterolateral to the lateral ocelli, in Eufriesea and Eulaema being separated from the lateral ocellus by about 0.5 ocellar diameters, while in both Exaerete and Aglae the tubercles are displaced posteriorly so they are separated from the lateral ocellus by about one ocellar diameter (e.g., Fig. 1). It is also noticeable that while in Eufriesea the concavity in which the tubercles are found formed between the compound eye, the lateral ocellus, and the posterior section of the vertex is essentially the same as in Euglossa, but in the other three genera the concavity becomes more depressed adjacent to the tubercle on its posterior side, especially in the cleptoparasitic genera Exaerete and Aglae. Furthermore, in Aglae (not figured here owing to a scarcity of specimens available for scanning electron microscopy) the tubercles are significantly less rised than in the rest of the tribe. In terms of coloration, in all instances the juxtocellar tubercles are dark brown, as in Euglossa, which in the case of Eulaema and some Eufriesea makes them somewhat harder to locate if it were not for the presence of the depressed concavity in which they reside. In species of these two genera the area posterior to the ocellar assemblage is very setose, often covering the juxtocellar tubercles and further hiding them from view. In no instance of the material reviewed were pores or cuticular openings found (e.g., Figs 5-7).

Such juxtocellar structures are not restricted to Euglossini, and were also found in other groups of bees as summarized here. 

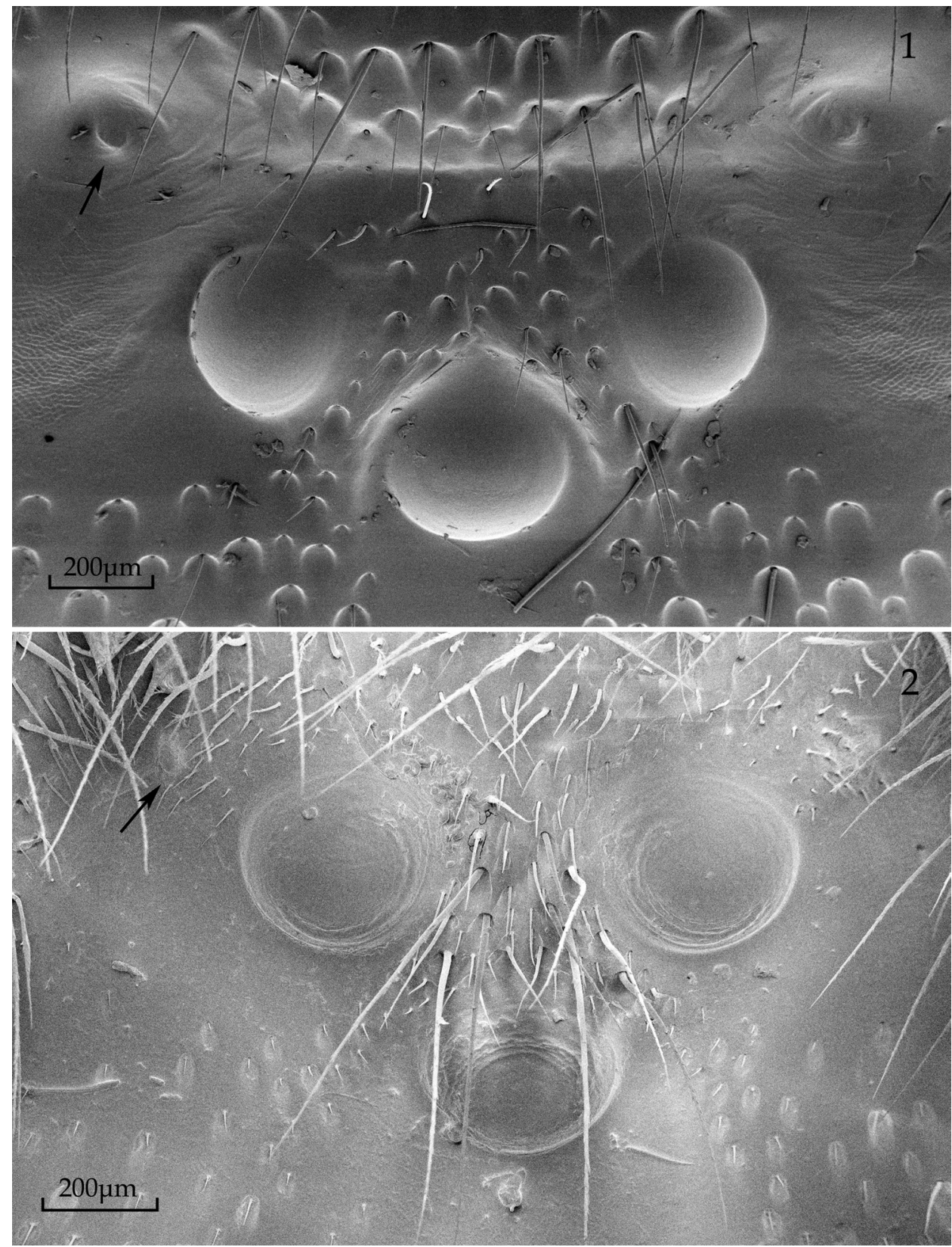

Figs 1-2: Ocellar area with juxtocellar structures indicated by arrow. - 1 male of Exaerete smaragdina (Guérin-Méneville). - 2 male of Euglossa imperialis Cockerell.

\section{Anthophorini:}

In Anthophora the juxtocellar structures are represented by low protuberances also located posterolaterally to the lateral ocelli, as described for Euglossa. As these protuberances do not rise as conspicuously as in the Euglossini, the term "tubercles" is less than ideal. The shape of these 
low protuberances varies among the species, in some of them appearing almost absent, but still with some form of noticeably wrinkled integument (distinctly different from the surrounding cuticle) always present in the posterolateral area of the lateral ocelli. Although also sitting in a shallow concavity, as in Euglossa, the concavity is not as evident and there is no bulky integument surrounding the ocelli. The structure is present in both sexes with no evident sexual variation (Fig. 8).
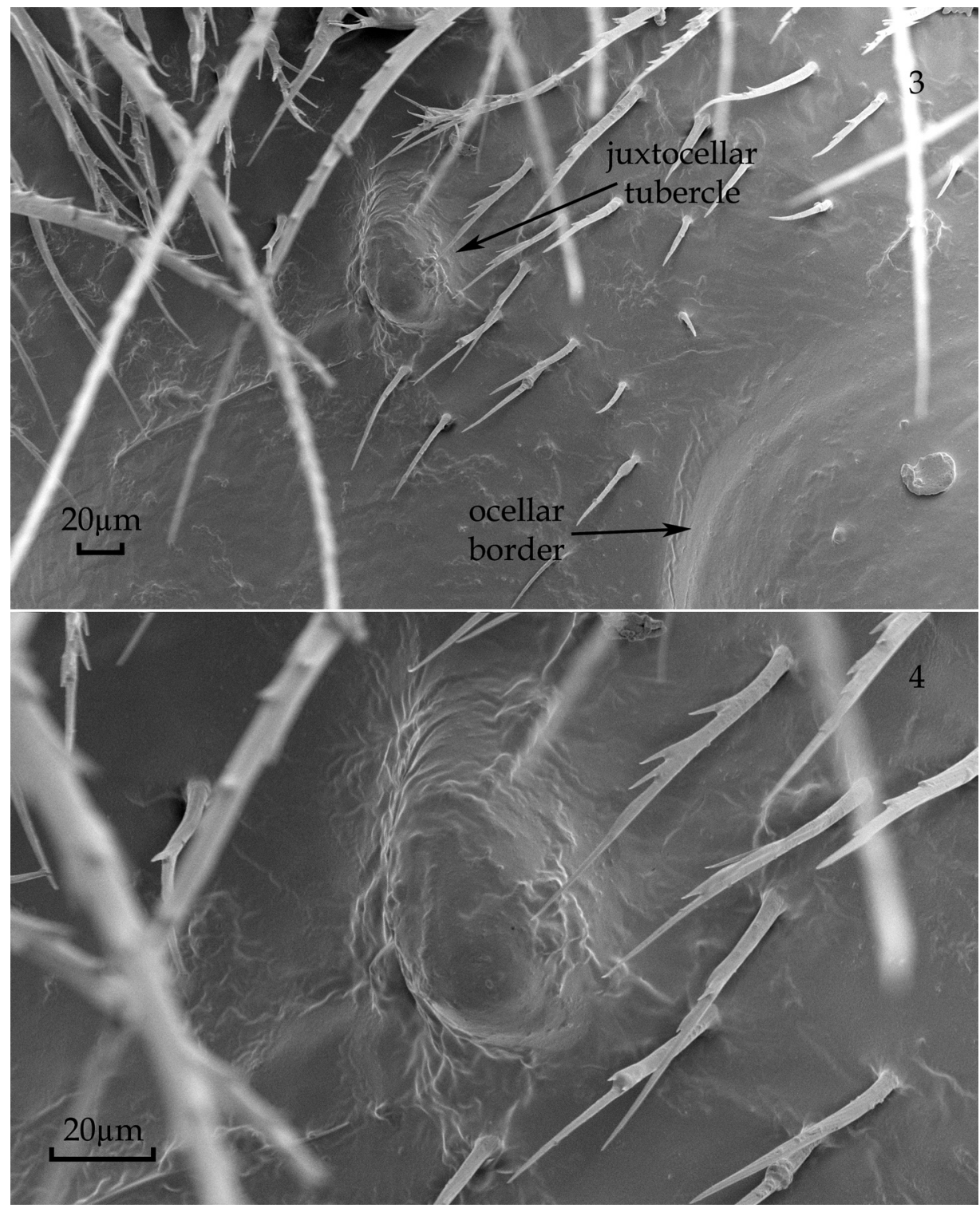

Figs 3-4: Juxtocellar tubercles of male of Euglossa imperialis CocKereLL. - 3 view of its position with respect to ocellus. -4 closer view showing integumental detail. 

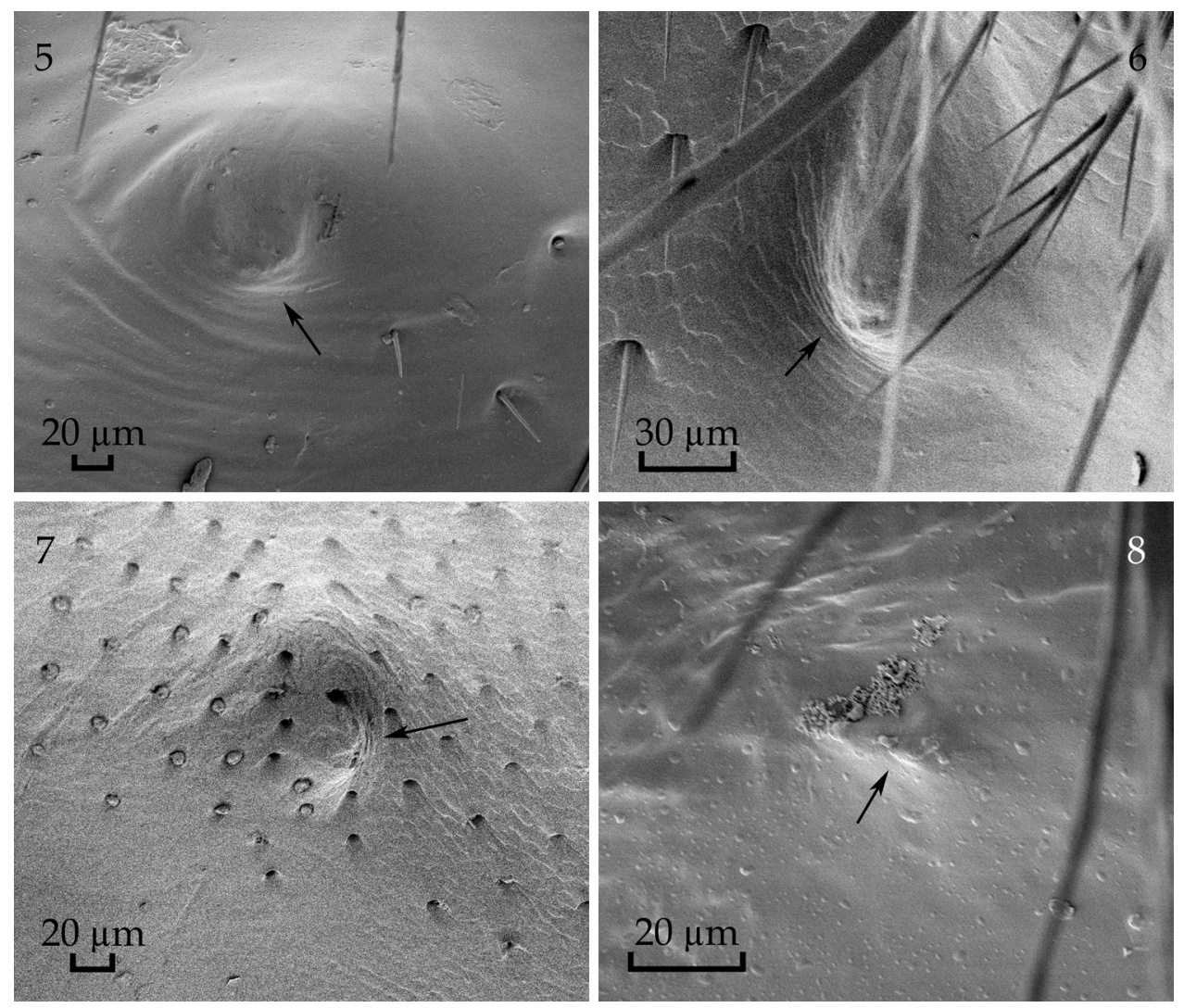

Figs 5-8: Juxtocellar structures in euglossine and anthophorine bees. -5 male of Exaeretesmaragdina (GuÉRINMÉNEVILLE). - 6 male of Eufriesea anisochlora (KIMSEY). - 7 male of Eulaema bombiformis (PACKARD) (dense setae covering structure removed). -8 male of Anthophora terminalis (Cresson). [Note: Owing to an effect of illumination in the electron microscope protuberances may appear as concavities and vice versa.]

\section{Centridini:}

In Centris there are very well developed juxtocellar tubercles, similar in shape as those seen in Eufriesea, which is to say, circular with the tip projecting laterally. They are also located posterolateral to the lateral ocelli with separation from the ocelli varying among species. The juxtocellar tubercles in Centris lie in a depressed area between the compound eye and the lateral ocellus, while the concavity described for Euglossini seems to be variable among species, even among sexes of some species, such as the one shown in figures 9 and 10; for the male there is not a very well demarcated concavity such as that described for Euglossa, while the female has the juxtocellar tubercle sitting in a deep concavity enclosing it.

\section{Eucerini:}

In Melissodes the juxtocellar tubercles are present and equivalent to the structure described above for the Centris male, and there seems to be no sexual differences (Fig. 11). In a variety of other Eucerini the tubercles are also present (e.g., Alloscirtetica, Anthedonia, Cemolobus, Eucara, Eucera, Peponapis, Tetraloniella, Thygater, Xenoglossa). 

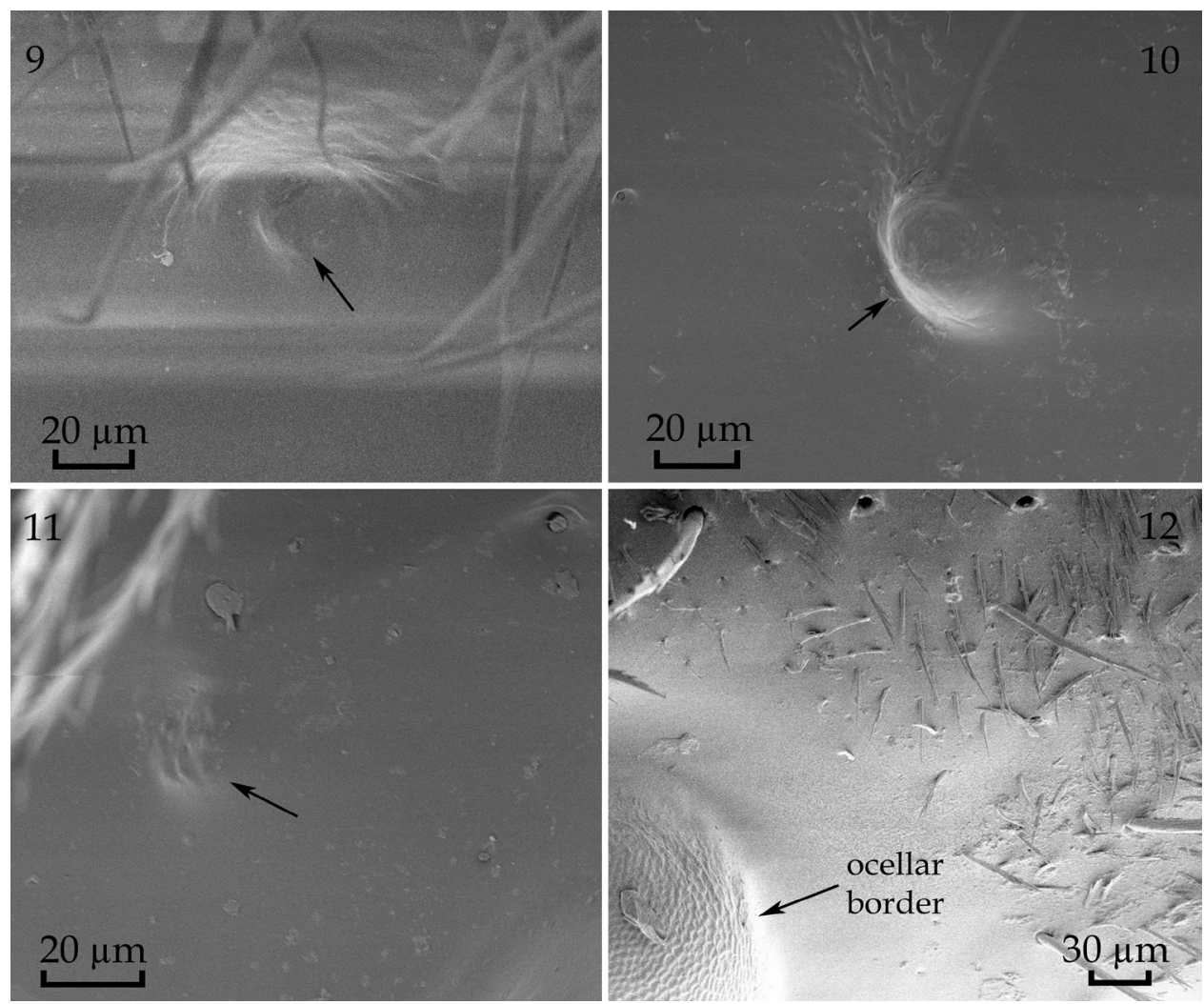

Figs 9-12: Juxtocellar structures (or lack thereof) in centridine, eucerine, and meliponine bees. -9 female of Centris birkmanni Friese. - 10 male of C. birkmanni. - 11 male of Melissodes tristis Cockerell. -12 female (worker) of Trigona fulviventris fulviventris GuÉRIN-MÉNEviLLE (juxtocellar structures absent). [Note: Owing to an effect of illumination in the electron microscope protuberances may appear as concavities and vice versa.]

\section{Other eucerite Apinae:}

Other groups of apine bees with noticeable juxtocellar structures include the Tapinotaspidini (Caenonomada, Chalepogenus, Monoeca, Lanthanomelissa, Paratetrapedia; also A. Aguiar, pers. comm.) and Emphorini (Alepidosceles, Ancylocelis, Diadasia, Melitoma, Ptilothrix).

\section{Corbiculate Apinae (sine Euglossini):}

Within the corbiculate clade juxtocellar structures are absent beyond the Euglossini. All of the specimens reviewed of Bombini, Apini, and Meliponini show unmodified integument where in the Euglossini juxtocellar tubercles are present (e.g., Fig. 12). The absence of the juxtocellar structures in the remainder of the corbiculate bees is also observed in specimens of the extinct tribes Electrobombini, Electrapini, and Melikertini, as well as in fossil specimens of Meliponini [species examined: Electrobombus samlandensis ENGEL, Thaumastobombus andreniformis ENGEL, Protobombus indecisus Cockerell, Electrapis meliponoides (ButTel-Reepen), Melikertesstilbonotus (EnGel), M. clypeatus Engel, Succinapis goeleti Engel, S. micheneri Engel, S. proboscidea Engel, Melissites trigona Engel, Liotrigonopsis rozeni Engel, Cretotrigona prisca (Michener \& Grimaldi), Proplebeia dominicana (Wille \& Chandler), P. tantilla Camargo et al., P. vetusta Camargo et al., Nogueirapis silacea (Wille)]. 


\section{Xylocopinae and Nomadinae:}

Representatives of Xylocopa and Ceratina (Xylocopinae) reviewed showed no sign of these structures, as was the case for specimens of several species of Nomada (Nomadinae). Beyond Apidae (sensu Michener, 2007) structures equivalent to the juxtocellar features described herein seem to be absent except in Colletidae where several groups of bees (e.g., Caupolicana, Paracolletes, Scrapter) show an array of fairly similar structures. A detailed morphological account of these structures is required although the potential secondary homology of these with those in Apidae seems dubious (i.e., they may prove to be primary homologues but are almost assuredly of independent origin).

\section{Discussion}

The juxtocellar structures described herein and detected primarily in Eugloss a show an interesting distribution among different groups of apine bees. There is certainly a somewhat conservative morphology within Euglossa, with slight variation in orientation and size. Some of the clearly defined infrageneric assemblages have somewhat distinct morphologies in juxtocellar design, such as Glossura + Glossuropoda with bigger, more noticeable juxtocellar tubercles than the rest of the Euglossa species, and the monotypic Dasystilbe in which the tubercles are not oblique as in the remainder of the genus. Several species in the subgenus Glossurella have the juxtocellar tubercles smaller and somewhat circular rather than as enlarged ovals; however, some others in this assemblage have these structures as observed in other groups within Euglossa. The utility of these structures in terms of phylogenetic impact will be addressed in a forthcoming phylogenetic analysis of infrageneric relationships of Euglossa (Hinojosa-Díaz, in prep.).

The juxtocellar structures as they appear in Euglossini, Anthophorini, Centridini, and Eucerini are also present in Emphorini and Tapinotaspidini, and perhaps in some other apid bee groups not studied at this time. As such, this distribution makes them an interesting structure in terms of phylogenetic assessment. Certainly as an isolated character their impact cannot be critically evaluated, nonetheless a cursory consideration of their distribution among Apidae is interesting. Given their absence in Xylocopinae and Nomadinae they may be a groundplan feature of Apinae. Within the corbiculate Apinae the evolutionary implications of these structures seems more apparent. The loss of this structure beyond Euglossini appears to be apomorphic and a further synapomorphy of the eusocial tribes (living and extinct), in complete agreement with current phylogenetic hypotheses for the corbiculates (sensu ENGEL, 2001a, 2001b; ScHUlTz et al., 2001; Cardinal \& Packer, 2007).

The juxtocellar structures are external integumental features easily seen with sufficient magnification. In Euglossa in particular they are easily spotted as their coloration contrasts noticeably with the surrounding integument; however, in groups of bees or species in which the vertex and area contiguous to the ocelli is densely setose, these structures are almost entirely obscured. It is even more challenging to determine the presence of juxtocellar structures in bees with strong and complex sculpturing in this area of the head, such as those in the Epeolini. Peculiarly, the juxtocellar structures seem to be only external morphological manifestations, with no pores that could represent glandular openings and with no associated internal cuticular projections; however, more detailed studies would be interesting as they may reveal some development connection, particularly given their proximity to the ocelli. 


\section{Acknowledgements}

This paper is part of the doctoral research of the first author, most of which has been carried out under the sponsorship of CONACYT (Consejo Nacional de Ciencia y Tecnología, México). Dr. Bruce Cutler provided invaluable help in the preparation of specimens for scanning electron microscopy and in the use of the machine, and Dr. Charles D. Michener provided a thorough review of an early draft. This paper is dedicated to Dr. Michener in celebration of his 90th birthday this year (22 September 2008). Partial support was provided by National Science Foundation grants EF-0341724 and DEB-0542909 (to M.S. Engel). This is a contribution of the Division of Entomology, University of Kansas Natural History Museum.

\section{References}

Cardinal, S. \& Packer, L. 2007: Phylogenetic analysis of the corbiculate Apinae based on morphology of the sting apparatus (Hymenoptera: Apidae). - Cladistics 23 (2): 99-118.

Cockerell, T. D. A. 1917: Some euglossine bees. - The Canadian Entomologist 49: 144-146.

Dressler, R. L. 1978: An infrageneric classification of Euglossa, with notes on some features of special taxonomic importance (Hymenoptera: Apidae). - Revista de Biología Tropical 26 (1): 187-198.

Dressler, R. L. 1982a: New species of Euglossa. II. (Hymenoptera: Apidae). - Revista de Biología Tropical 30 (2): 121-129.

Dressler, R. L. 1982b: New species of Euglossa. III. The bursigera species group (Hymenoptera: Apidae). - Revista de Biología Tropical 30(2): 131-140.

Dressler, R. L. 1982c: New species of Euglossa. IV. The cordata and purpurea species groups (Hymenoptera: Apidae). - Revista de Biología Tropical 30 (2): 141-150.

Engel, M. S. 2001a: A monograph of the Baltic amber bees and evolution of the Apoidea (Hymenoptera). - Bulletin of the American Museum of Natural History 259: 1-192.

ENGEL, M. S. 2001b: Monophyly and extensive extinction of advanced eusocial bees: Insights from an unexpected Eocene diversity. - Proceedings of the National Academy of Sciences, USA 98 (4): 1661-1664.

Hinojosa-Díaz, I. A. \& Engel, M. S. 2007: Two new orchid bees of the subgenus Euglossella from Peru (Hymenoptera: Apidae). - Beiträge zur Entomologie 57 (1): 93-104.

Michener, C. D. 2007: The Bees of the World [2nd Edition]. - Pp. xvi+[i]+953. - Baltimore: Johns Hopkins University Press.

Moure, J. S. 1967: A check-list of the known euglossine bees (Hymenoptera, Apidae). - Atas do Simpósio sôbre a Biota Amazônica 5 (Zoologia): 395-415.

Moure, J. S. 1989: Glossuropoda, novo subgênero de Euglossa, e duas espécies novas da Amazônia, do mesmo subgênero (Apidae - Hymenoptera). - Memórias do Instituto Oswaldo Cruz 4: 387-389.

Schultz, T. R.; Engel, M. S. \& Ascher, J. S. 2001: Evidence for the origin of eusociality in the corbiculate bees (Hymenoptera: Apidae). - Journal of the Kansas Entomological Society 74 (1): 10-16.

\section{Authors' address:}

Mr. Ismael A. Hinojosa-Díaz and Prof. Dr. Michael S. Engel

Division of Entomology, Natural History Museum

and Department of Ecology \& Evolutionary Biology

1501 Crestline Drive - Suite 140

University of Kansas

Lawrence, Kansas 66049-2811

United States

\section{Subject editor:}

Prof. Dr. H. H. DATHe 